\title{
The Joy of Visual Metaphors
}

\author{
Veronika Reichl \\ Strelitzer Straße 51 \\ 10115 Berlin, Germany \\ veronika@reichl.net
}

\section{INTRODUCTION}

With the help of an experimental artistic approach and in reference to positions from semiotics and linguistics, I investigate under which conditions visualisations are experienced as interesting and charming. After extensive research in the semiotic fundamentals of the visualisation of theoretical texts (Reichl, 2008; Reichl, 2009), this research project is concerned with what makes visualisations of theoretical concepts interesting and enjoyable. A special focus lies in this context on the designs of visual metaphors.

The experimental approach of this investigation consists in visualising philosophical text passages through animated films. The films present spoken texts and animated film-scenes simultaneously. These films were shown to a group of scholars of philosophy and a group of design students, and interviews on their interpretation and their liking of the films were conducted.

From creating the animated films and analysing the interviews in reference to semiotic and linguistic positions derive several insights on what makes visualisations interesting and joyful.

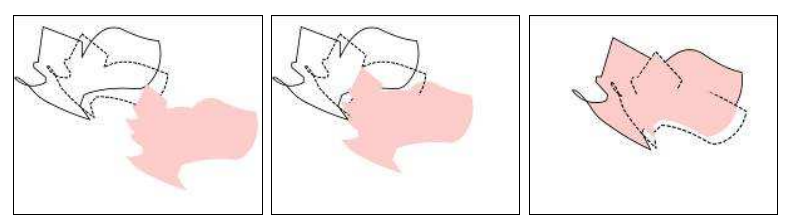

Figure 1: Stills from the "Film Spinoza"

\section{VISUAL METAPHOR AND INTERPRETATION}

One of the most important hypotheses of the project is that the delight in the films derives for the most part from the potential of the visualisations for creative interpretation. Certain designs of visualisations allow for operations of interpretation that are experienced as especially delightful. This delight emerges not only from understanding the reference between text and visualisation but from the process of creating an inventive interpretation of it.

Within visualisations metaphorical references are the most important means of creating meaning. They are the basis of all interpretation. The design of visual metaphors plays a crucial role for the interpretability and the joy of the interpretation.

The mode of function of visual metaphors is closely related to the mode of function of linguistic metaphors. For allowing for an explainable interpretation it is necessary that (visual as well as linguistic) metaphors can be traced back to common metaphors (mostly known from language). Otherwise the interpretation remains vague.

Pictorial and filmic metaphors appear as singular gestalts showing spatial objects in motion. Singular gestalts yields the possibility of defining many details of these gestalts and thereby extent and define details of the visual metaphors these gestalts represent. The interpretation of such details in reference to the main idea of the metaphor and in reference to each other can make the visualisation interesting and inspiring.

Employing singular gestalts as metaphors (and not symbols like words) also causes some nonsensical aspect in the relation between text and visualisation. This nonsensical aspect can make the visualisation for some people more enjoyable, while others feel irritated. The design of the visualisation can stress or minimize the nonsensical aspect.

\section{REFERENCES}

Deleuze, G. (1990) The Logic of Sense. Columbia University Press, New York.

Lakoff, G. \& Johnson, M. (1981) Metaphors we live by. University of Chicago Press, Chicago. 
Reichl, V. (2008) Sprachkino (Language-Cinema) Merz \& Solitude, Stuttgart.

Reichl, V. (2009) How do pictorial representations refer abstract content? In Malins, J., Design Connexity: Eights International Conference of the
European Academy of Design. Robert Gordon University, Aberdeen.

Peirce, C., (1998). Phänomen und Logik der Zeichen (Logic of signs). Suhrkamp, Frankfurt am Main. 